\title{
HYDROLETHALUS SYNDROME
}

Aradhana Kankane ${ }^{1}$, Arvind Kankane ${ }^{2}$, Tarun Chandra ${ }^{3}$.

1. Assistant Professor, Department of Pediatrics, Maharani Laxmibai Medical College Jhansi, Uttar Pradesh, India.

2. Assistant Professor, Department of Neurology, Maharani Laxmibai Medical College Jhansi, Uttar Pradesh, India.

3. Senior Resident, Department of Pediatrics, Maharani Laxmibai Medical College Jhansi, Uttar Pradesh, India.

\section{CORRESPONDING AUTHOR}

\section{Dr. Aradhana Kankane,}

Kankane Neuro \& Child Care Centre,

Opp. Medical College Jhansi, Uttar Pradesh.

Email-draradhana_2002@rediffmail.com

\section{HOW TO CITE THIS ARTICLE:}

Aradhana Kankane, Arvind Kankane, Tarun Chandra. "Hydrolethalus Syndrome". Journal of Evolution of Medical and Dental Sciences 2013; Vol2, Issue 24, June 17; Page: 4455-4458.

INTRODUCTION: Hydrolethalus Syndrome (HLS) is a rare lethal genetic syndrome, recognized as a consequence of a study on Meckle syndrome in Finland . ${ }^{1}$ HLS is characterized by multiple developmental defects of fetus which include fetal hydrocephalus, agenesis of corpus callosum, absent midline structures of brain, Cleft lip and cleft palate, defective lobulation of lungs, micrognathia and very characteristic abnormality of polydactyly. About $80 \%$ of patients have polydactyly, in hands it is postaxial and preaxial in feet with duplicated big toe. A highly characteristic hallux duplex is seen in almost no other situation.$^{2}$ Club feet is also common.

KEY WORDS: Hydrolethalus, Hydrocephalus, Polydactyly.

REPORT OF CASE: A 37 weeks term male, 3200 grams was born to a 26 years old primipara Hindu Indian by caesarian section out of non-consanguineous marriage. Mother had a history of polyhydramnios with no history of fever or drug intake during antenatal period. The cry was delayed by 10 minutes, baby developed respiratory distress soon after birth and was admitted to NICU and survived only for 18 hours. The newborn had facial dimorphism in the form of left sided cleft lip, widely spaced eyes \& low set ears (Fig-1).

Other malformations included polydactyly in all four limbs in the form of postaxial in hands \& preaxial in feet, with hallux duplex in both lower limbs which is highly characteristic of HLS (Fig 2). Baby's length was $53 \mathrm{~cm} \&$ Head circumference was $38 \mathrm{~cm}$ which is more than 97percentile. All the sutures including metopic were open. Cranial USG (ultrasonography) revealed cerebellar hypoplasia with underdeveloped vermis and fourth ventricle communicating with cisterna magna (Fig-3). On echo cardiography no cardiac abnormality was detected. X-ray chest revealed well formed lungs. On basis of clinical features and cranial USG, diagnosis of Hydrolethalus syndrome was made.

DISCUSSION: Hydrolethalus syndrome -1(HLS-1) is caused by homozygous mutation with autosomal recessive inheritance in HYLS-1 gene on chromosome 11q24. ${ }^{3}$ This was discovered in Finland with incidence of at least $1: 20000$ in Finland. ${ }^{1}$ nnly few of such cases are reported in 
literature from elsewhere in world.2-7 HLS is characterized by Hydrocephalus with absent midline structures of brain. The foramen magnum is keyhole shaped. In hydrocephalic cases the hemispheres, lie separated in the bottom of the skull and the upper midline structures, corpus callosum \& septum pellucidum are absent. The gyration of brain is often grossly abnormal. The pregnancy is complicated by poly hydramnios and often preterm delivery. About $70 \%$ of patients are still born and those born alive survive a few minutes to a few hours at most. Micrognathia is a common feature and about half the cases have cleft palate or lip. Some cases have bifid nose. The eyes are wide spaced and sometimes also hypoplastic and deep set. Malformed or hypoplastic lungs are frequent findings. The trachea or the bronchi or both are stenotic or rarely dilated. Half of the patients have a congenital heart defects in form of a large VSD combined with ASD. Some cases have unilateral or bilateral hydronephrosis but structures of the kidneys are normal. Male patients sometimes have hypospadias, half of female have duplicate uterus with associated malformation of the vagina. ${ }^{8}$ About $80 \%$ of patients have polydactyly. In the hands it is postaxial, but in the feet, it is typically preaxial with duplicated big toe. Even if there is only one big toe it is often bent medially, club feet is also common. In some cases the extremities are short \& joints of knees are abnormal. Unilateral agenesis of diaphragm, omphalocele, agenesis of tongue, syndactyly are occasional anomalies. Absent midline structures of brain, facial anomalies, respiratory tract, cardiac and genital anomalies can be regarded as defects of the midline developmental field. ${ }^{8}$

Other similar syndromes such as Meckle syndrome, trisomy 13 etc. is needed to rule out. Meckel syndrome with hydrocephalus differs from hydrolethalus syndrome principally in cystic and fibrotic changes of the kidney and liver. ${ }^{1}$ Trisomy 13- presents with similar anomalies but they often have microcephaly, cystic kidneys, and only rarely polydactyly in infant. ${ }^{9}$

Hydrolethalus syndrome can be recognized before birth by prenatal ultrasound. ${ }^{10}$ The hydrocephalus and brain malformation suggest the diagnosis.

CONTRIBUTIONS: All authors have contributed in clinical diagnosis, management of patient and preparation of manuscript.

\section{CONFLICT OF INTEREST: None \\ ROLE OF FUNDING SOURCE: None}

\section{REFERENCES:}

1. Salonen R, Herva R, Norio R. The hydrolethalus syndrome: delineation of a 'new' lethal malformation syndrome, based on 28 patients. Clin. Genet 1981; 19:321-330 [Pub Med: 7028327, related citations] [Full Text: Pub get]

2. Krassikoff N, Konick L, Gilbert EF. The Hydrolethalus syndrome. Birth defects 1987; XXIII (1): 411-9.

3. Mee L, Honkala H, Kopra O, Vesa J, Finnila S, Visapaa I, Sang T-K, Jackson G. R, Salonen R, Kestila M, Peltonen L. Hydrolethalus syndrome is caused by a missense mutation in a novel gene HYLS1. Hum. Molec. Genet 14: 1475-1488, 2005. [Pub Med: 1583405, related citations] [Full Text: High Wire Press, Pubget].

4. Adetoro A A, Komolafe F, Anjorin A. Hydrolethalus syndrome in consecutive African siblings. Pediatr Radiol 1984; 14:422-4. 
5. Toriello HV, Bauserman SC. Bilateral Pulmonary agenesis: association with the hydrolethalus syndrome and review of the literature from a developmental field perspective. Am J Med Genet 1985; 21:93-103.

6. Anyane - Yeboa K, Collins M, Kupsky W, Maidman J, Malin J, Yeh M. Hydrolethalus (SalonenHerva-Norio) syndrome: further clinicopathological delineation. Am J Med Genet 1987; 26:899-907.

7. Aughton DJ, Cassidy SB. Hydrolethalus syndrome: report of an apparent mild case, literature review, and differential diagnosis. Am J Med Genet 1987; 27:935-42.

8. Optiz J M, Gilbert EF, Editorial comment: CNS anomalies and the midline as a "developmental field". Am J Med Genet 1982; 12:443-55

9. Buchman H, Clark R. D, Salahi W .Holoprosencephaly and Polydactyly: a possible expression of the hydrolethalus syndrome. J. Med. Genet 1990; 27:50-52. [Pub Med : 2407845,related citations]

10. Hartikainen - Sorri A L, Kirkinen P, Herva R. Prenatal detection of hydrolethalus syndrome. Prenat Diagn: 1983; 3:219.

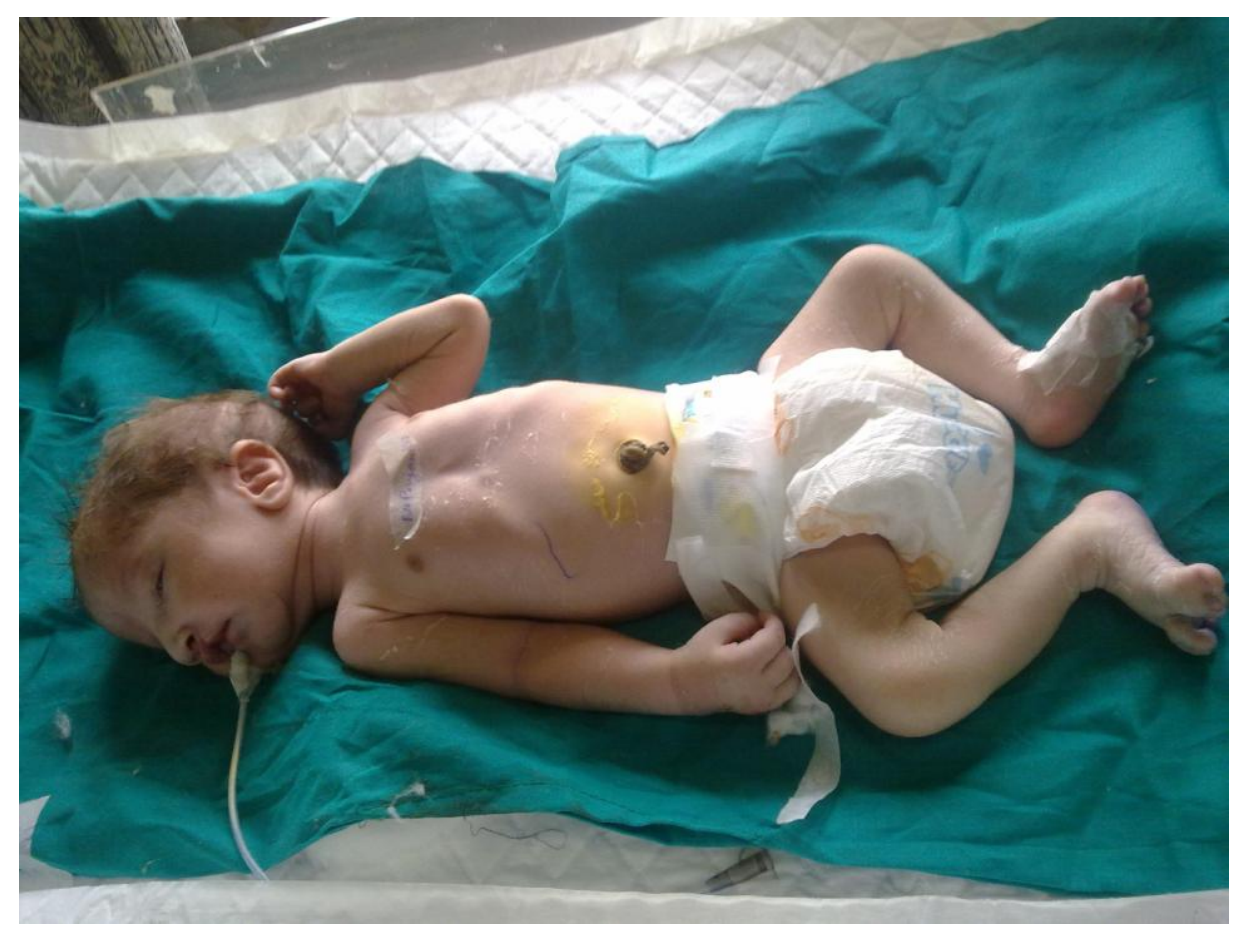

FIG 1:-The newborn with left sided cleft lip, widely spaced eyes and low set ears. 


\section{CASE REPORT}

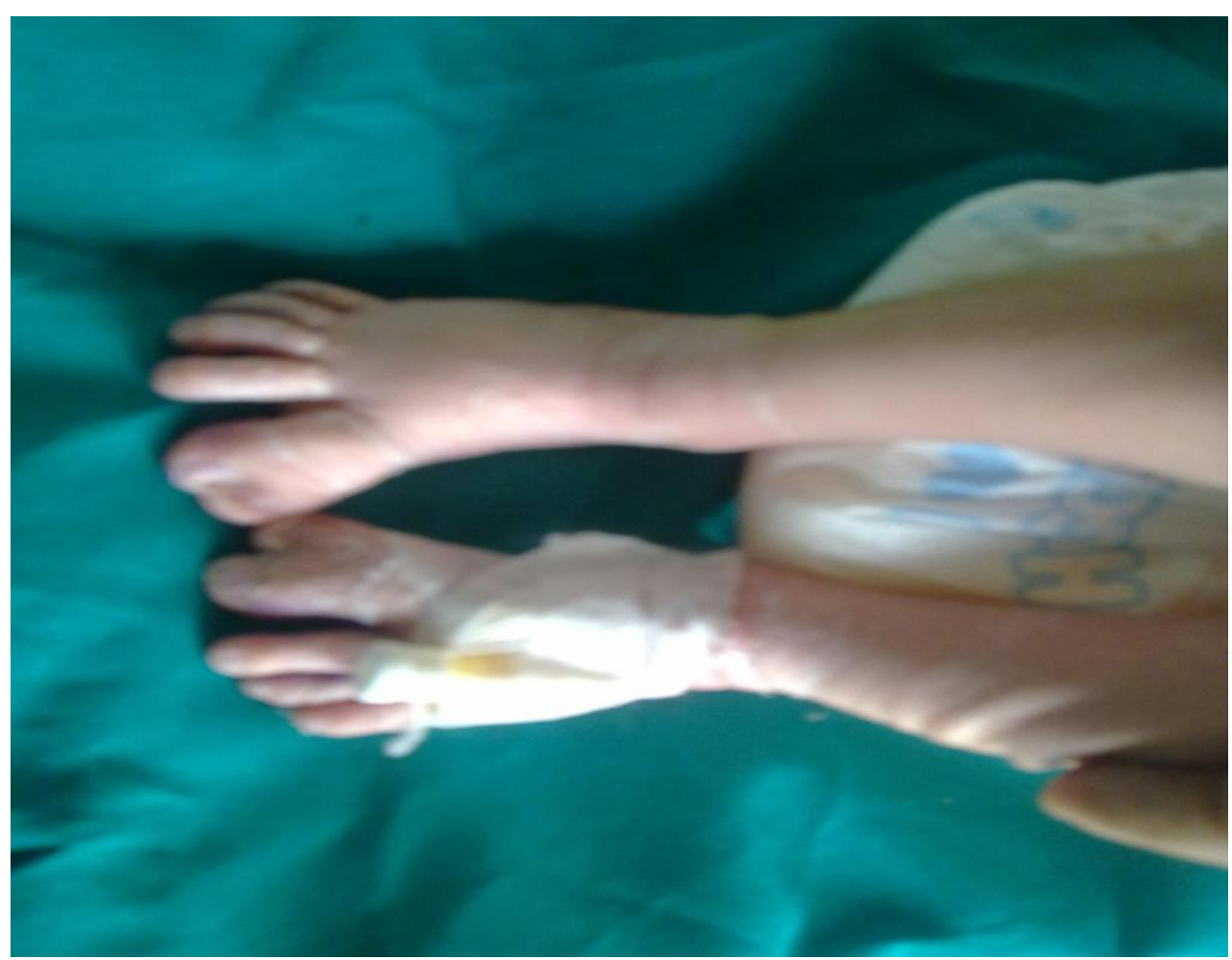

FIG 2:-The hallux duplex in both lower limbs.

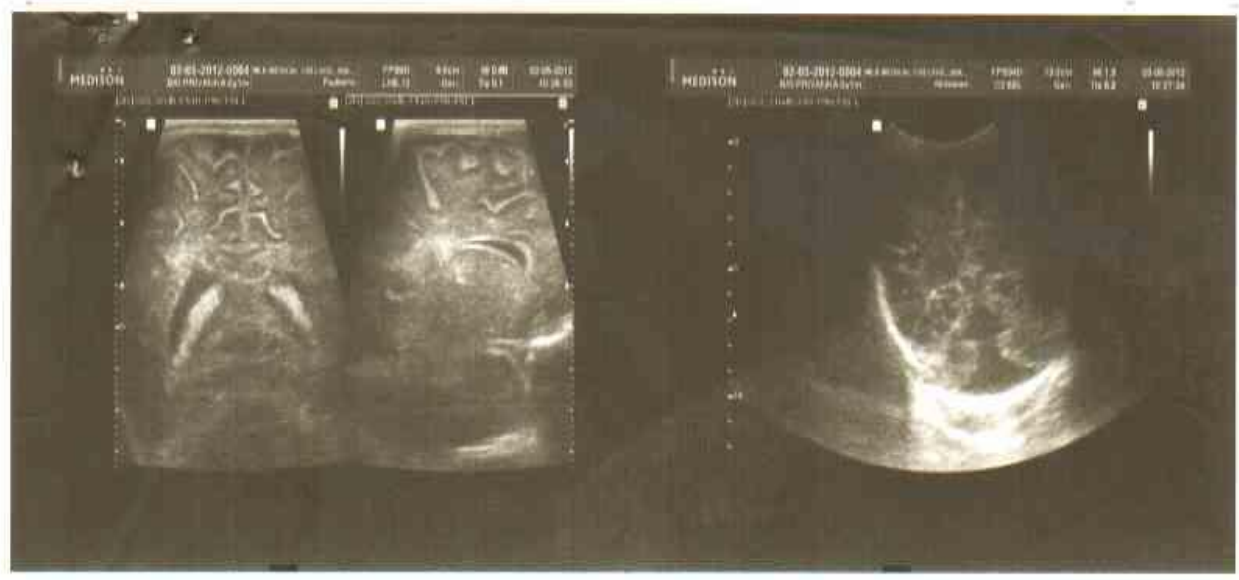

FIG 3:-Cranial USG revealed cerebellar hypoplasia and fourth ventricle communicating with cistern magna. 